\title{
Experimental Investigation of Heat Transfer characteristics Enhancement through Grooved Tube
}

\author{
Pranita Jagtap* and P. E. Chaudhari \\ Mechanical Engineering department, MIT College of Engineering, Kothrud, Pune-411038, Maharashtra, India
}

Accepted 15 June 2016, Available online 20 June 2016, Special Issue-5 (June 2016)

\begin{abstract}
Heat transfer in pipe flow is one of the wide applications that are used in industry. Among the various applications used in industry, heat exchangers are one of the most widely used applications. The principle of heat exchangers is to allow the heat transfer between any two fluids without physical contact between them having different temperatures. In saving energy and material resources in industry, heat transfer rise plays a vital role. Because of saving energy and material resources in industry, there is a need of design of compact heat exchangers that has low weight and high performance. To obtain more compact and efficient units enhanced surfaces are successfully used in the heat transfer industry. Due to simple fabrication and effective heat transfer enhancement, now day's grooved tubes are widely used in the industry. The use of grooved tubes is found in evaporated condensers for saline water distillation, steam turbine power. In this study the forced convection heat transfer characteristics from grooved tube is investigated experimentally. The effect of variation in pitch of groove on heat transfer characteristics is investigated with variation in mass flow rate of air and heat input. Additionally the effect of variation in pitch of groove on pressure drop across test section is investigated with variation in mass flow rate of air and heat input. Whole experimentation has been carried out under turbulent flow condition.
\end{abstract}

Keywords: Thermal performance; Grooves Tubes; Forced Convection, Heat transfer coefficient.

\section{Introduction}

The active and passive methods are the two methods used to enhance the heat transfer. The external sources are required for active method whereas working fluid additives and different surface geometries are required for passive method. Many numerical and experimental studies were carried out to find out the importance of the heat transfer enhancement. The objective of this activity is to obtain a more efficient heat exchangers and thermal heat transport devices for their industrial and other applications, with the main objective is to provide material, economic saving and energy for users of technology of heat transfer enhancement. In these days, grooved tubes are mostly used in new heat exchangers, as they are effective in heat transfer enhancement.

In high efficiency refrigeration and air conditioning systems, now day's micro-grooved tubes are playing essential role. These tubes generally have grooves near about $0.2 \mathrm{~mm}$ deep with about a $0.5 \mathrm{~mm}$ pitch which may be arranged in a variety of patterns around the inner walls. Now a days, tubes with axial, helical, crosshatched and herringbone patterns are available. From the past studies, it has come to our knowledge that micro-grooved tubes helps in achieving enhanced

${ }^{*}$ Corresponding author: Pranita Jagtap heat transfer coefficients compared to smooth tubes accompanied with slight increase in pressure loss. This effect is more dramatic at low mass fluxes. In coolers, condensers or evaporators for cooling systems and air conditioning micro grooved tubes are used.

These tubes combine greater efficiency with more compact heat exchangers. Therefore, they require less refrigerant load. Such technology is capable of benefiting the increment of the heat transfer without similar increase in the pressure drop, majorly in twophase applications. Early in the 1970's, Hitachi Cable pvt. Ltd. applied the use of copper tubes of small diameter consisting of internal micro grooved surface. Since then, these tubes have seen a great application in the heat exchangers commercial market and have replaced the smooth tubes.

The main aim of the present research work is to investigate the effect on heat transfer performance of the modified surface (helically grooved) of the tube on the enhancement in heat transfer. The prospect of using the helically grooved tube is for reducing the thickness of the boundary layer which is focused at better fluid mixing near the tube wall caused by the secondary flows from the wall to the core flow. 


\section{Literature Review}

Kadir et al. worked on the enhancement of convective heat transfer in a single-phase turbulent flow by using helically grooved tubes. In the evaluation, the isothermal friction and thermal performance factor is calculated under the effects of pitch-to-diameter ratio and rib-height to diameter ratio of helically grooved tubes on the heat transfer enhancement. After studying for the turbulent flow, results shows that the thermal performance and the heat transfer characteristic of the grooved tube are increased in comparison with plane tube.

Jacqueline Biancon Copetti et al. have studied heat transfer characteristics and friction characteristics for single-phase flow (water) in micro-grooved tubes. The performance analysis with a $4.76 \mathrm{~mm}$ radius micro-fin tube for thermal and hydraulic behavior under the laminar and turbulent flow was carried out experimentally. In the heating tests, different operational conditions were considered. The pressure drop and flow rate, inlet and outlet temperatures and various wall temperatures along the tube, were measured. The higher heat transfer performance shows by micro-grooved tube than the smooth tube. About $80 \%$ increment shows in heat transfer coefficient.

Takahiro Adachi et al. studied correlation between pressure drop in channels with periodically grooved parts and heat transfer along the stream wise direction is investigated for different channels configurations by considering fully developed flow. Heat transfer is improved after the divergence with enhancement of pressure drop. Efficiency defined as ratio of heat transfer enhancement to the pressure drop enhancement. It is seen that the channels with expanded grooves perform efficiently, while the channels with contracted groove inefficient.

M. Greiner et al. have studied direct numerical simulations of 3D flow and enhanced convection in a channel with transverse, symmetric grooves in two opposite walls are performed using the spectral element technique. The flow is driven by constant pressure gradient. Results are presented for Reynolds no. range $180<\operatorname{Re}<1175$. A series of flow transitions is observed as the Reynolds number is increased, from steady two-dimensional flow, to traveling two arid three-dimensional wave structures, and finally to the three-dimensional mixing. Periodic ejection of slow moving fluid from the grooves causes significant flow rate unsteadiness. Three-dimensional simulations predict friction factor and Nusselt number values to within $20 \%$ of measured values over the narrow Reynolds number range where overlapping data exists. Two-dimensional simulations are found to be inadequate to transport in this channel for $\operatorname{Re}>400$.

I.S.Park, et al. have developed a 3D heat transfer characteristics analysis procedure for the coupled evaporating/condensing films going down along the inner/outer walls of vertical grooved tube has developed. The analysis is successful in results the free location of surface along with the amount of condensate and another major 3D characteristic.

Most of the condensation is observed to take place on bare place of groove surface and shows that how the heat transfer characteristics are improved by grooved surface. The results are indicated for various groove densities and operating condition. The optimum groove number looks to vary with the temperature difference of two sides. The effect of surface tensions also discussed.

\section{Development of experimental Set up}

The experimental setup generally consists of three part; the test section, air supply unit with necessary adoption and measuring devices. The air supply unit and its accessories consist of a blower, flow control valves, orifice meter, inclined tube differential manometer and grooved tubes. Heater is mounted on the grooved tube and space between them is filled with the silicon paste to transfer the uniform heat to the tube. Arrangement has been made to vary heat input by connecting the band heater through the dimmerstat to main supply. The amount of electrical energy supplied to heater can be measured by connecting the voltmeter and ammeter in between heater. The flow control valve has been connected at the downstream of the tube to vary the flow. The schematic arrangement of the experimental set up is as shown in figure 1 .

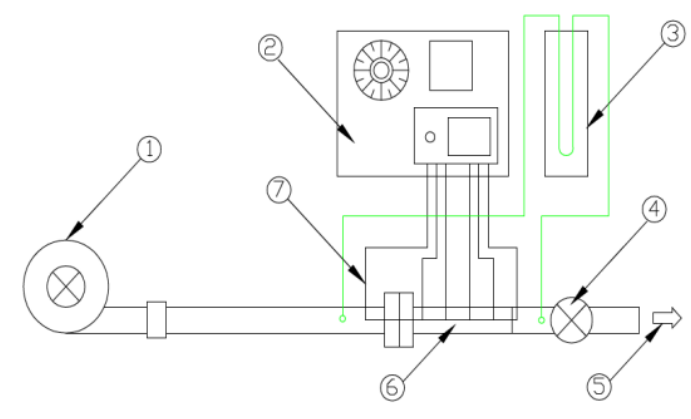

Fig.1 Schematic layout experimental setup. 1) Blower, 2) Control Panel, 3) Manometer, 4) Control Valve, 5) Air Flow, 6) Test Section, 7) Temperature Sensor

\subsection{Test Tubes}

The test section is as mentioned above consist of two different grooved tubes, its specifications as follows

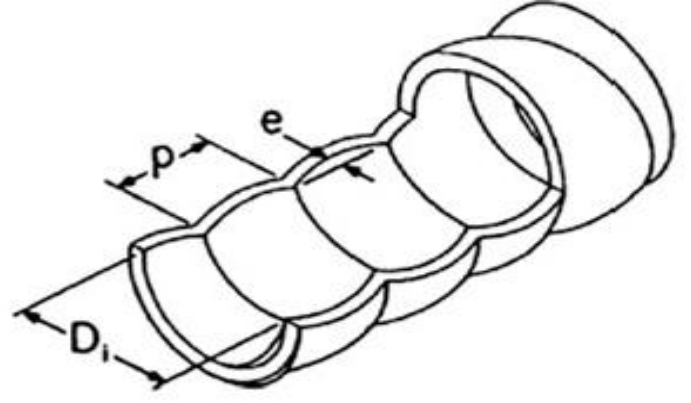

Fig. 2 Test Section- Grooved Tubes 
1. Tube material: Copper

2. Outside Diameter: $\mathbf{- 3 1 . 0} \mathrm{mm}$

3. Tube Thickness:-1 mm

4. Tube Length: - 2 feet

5. Grooved per feet :- $12 / 20$

6. Set 1 - Grooved per feet $=12$

7. Set $2-$ Grooved per feet $=20$

\subsection{Test Methodology}

1. Make sure that connections of the thermocouple are properly attached with the surfaces whose temperature is to be measured.

2. Switch on the Heater input and Centrifugal Blower input.

3. Using rheostat increase the supplied air heater input.

4. Start taking readings with time, set as zero

5. The blower is started and mass flow rate of air is adjusted as per requirement with the help of gate valve to have turbulent flow.

6. The mass flow rate of air is measured with the help of orifice meter.

7. Pressure difference between outlet and inlet side of the orifice meter is recorded with the help of $U$ Tube Manometer and attached scale.

8. Before taking the readings the steady state condition is maintained. Initially the readings on plain tube and then for grooved tube alone were taken. This is to validate and compare the performance of grooved tube with plain tube.

9. The temperature readings $\mathrm{Ti}$ (Ambient temperature), T7 (Air temperature at inlet side), T8 (Air temperature at outlet side), and T1 to T6 (temperatures at different location in test section) were recorded with the help of multimeter present with the apparatus.

Experimental Evaluation of thermal performance characteristics is carried out by varying the heat input from $25 \mathrm{~W}$ to $100 \mathrm{~W}$ in the step of $25 \mathrm{~W}$. Readings are taken at steady state. Heater is placed between two test plates. Whole test set up is mounted vertically. Voltage supplied is varied with the help of Variac dimmerstat.

\subsection{Test Parameters and Calculations}

Experimentation was performed on the circular pipe at various pitches of grooved tubes.

Table 3.1 Test parameters

\begin{tabular}{|c|c|}
\hline Parameter & Description \\
\hline Heat load $(\mathrm{W})$ & $25 \mathrm{~W}, 50 \mathrm{~W}, 75 \mathrm{~W}, 100 \mathrm{~W}$ \\
\hline Time & To reach up to Steady State \\
\hline
\end{tabular}

All the required components were assembled and experimental setup was developed. The required instruments were attached at proper configuration and the setup is prepared for the experimentation.

\subsection{Data Reduction}

Heat Supplied $(\mathrm{Q})=\mathrm{V} \times \mathrm{I}$

Heat Transfer coefficient (hth) $=Q / \mathrm{A}(\Delta T s-\Delta T \mathrm{a})$

Discharge through orifice $(\mathrm{q})=C d A o \sqrt{2 \mathrm{gha}}$

Nusselt Number $(\boldsymbol{N u})=0.023 \boldsymbol{R e}^{0.8} \mathbf{P r}^{0.4}$

Heat Transfer coefficient $\left(\mathrm{h}_{\text {th }}\right)=(N u) / k \mathrm{~L}$

\section{Results and Discussion}

The effect of grooves on tube on the heat transfer characteristics are presented in both terms of Nusselt number and heat transfer coefficient for plane tubes at the same Reynolds numbers. The Nusselt number and heat transfer coefficient is calculated by varying Reynolds number.

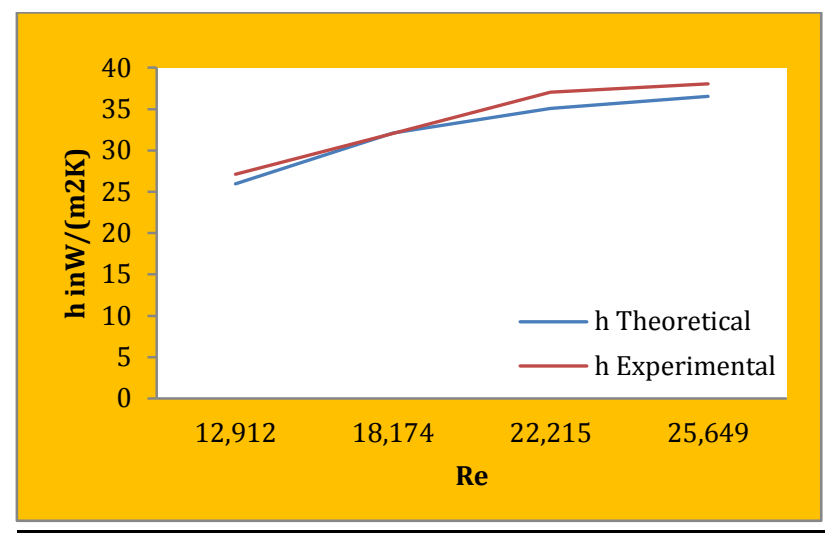

Fig.3 Comparison between of $h_{\text {th }}$ and $h_{\text {exp }}$ for plane tube

Heat transfer coefficient calculated by experimental method and theoretical method is similar for plane tube. From Figure no. 3, it can be said that experimental setup is validated.

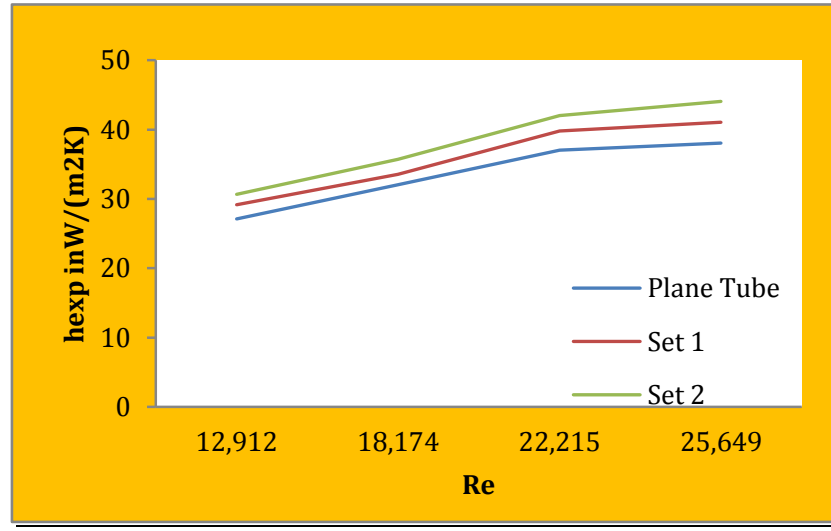

Fig.4Reynolds Number verses Heat transfer coefficient at 25W for different tubes

The above graph of heat input 25 Watt shows that grooved tubes shows increment in heat transfer coefficient. Set1 (Grooved pitch-12 per feet) shows $6.89 \%$ in comparison with plane tube. Set2 tube (Grooved pitch-20 per feet) shows $13.56 \%$ in comparison with plane tube. 


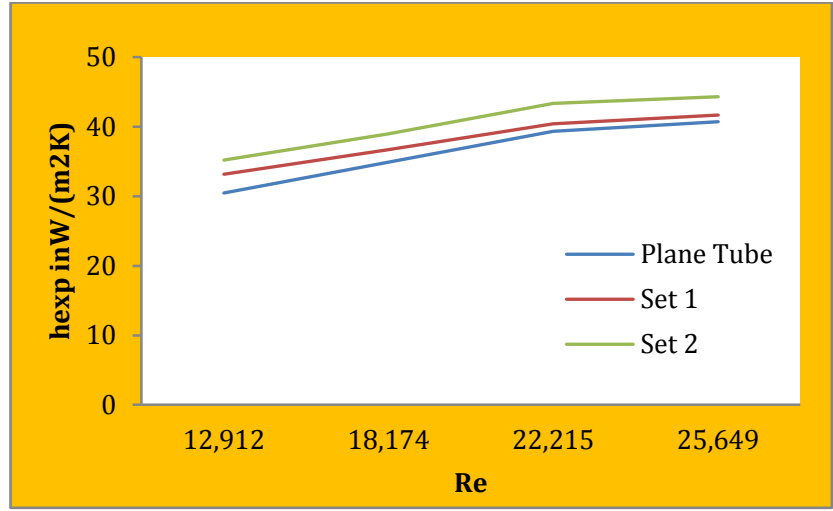

Fig.5Reynolds Number verses Heat transfer coefficient at 50W for different tubes

The above graph of heat input 50 Watt shows that grooved tubes shows increment in heat transfer coefficient. Set1 tube shows $4.48 \%$ in comparison with plane tube and Set 2 tube shows $11.30 \%$ in comparison with plane tube.

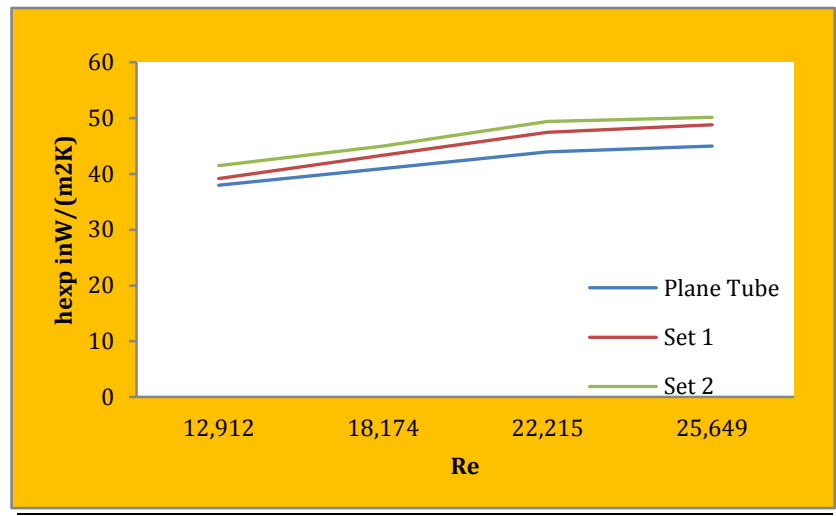

Fig.6 Reynolds Number verses Heat transfer coefficient at 75W for different tubes

The above graph of heat input 75 Watt shows that grooved tubes shows increment in heat transfer coefficient. Set1 tube shows $6.49 \%$ rise in comparison with plane tube and Set2 tube shows $10.84 \%$ in comparison with plane tube.

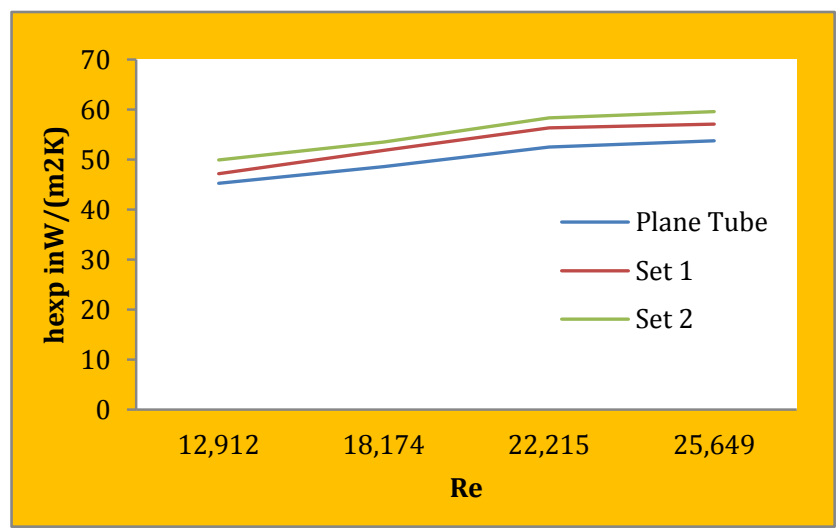

Fig.7 Reynolds Number verses Heat transfer coefficient at $100 \mathrm{~W}$ for different tubes
The above graph of heat input 100 Watt shows that grooved tubes shows increment in heat transfer coefficient. Set1 tube shows $6.13 \%$ rise in comparison with plane tube and Set2 tube shows $10.55 \%$ in comparison with plane tube.

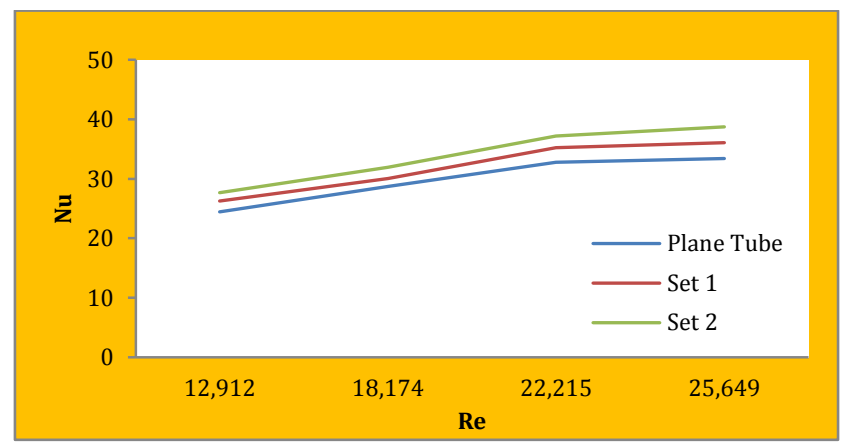

Fig.8 Reynolds Number verses Nusselt Number at 25W for different tubes

The above graph of heat input 25 Watt shows that grooved tubes shows increment in Nusselt number. Set 1 tube shows $6.89 \%$ in comparison with plane tube and Set 2 tube shows $13.54 \%$ in comparison with plane tube.

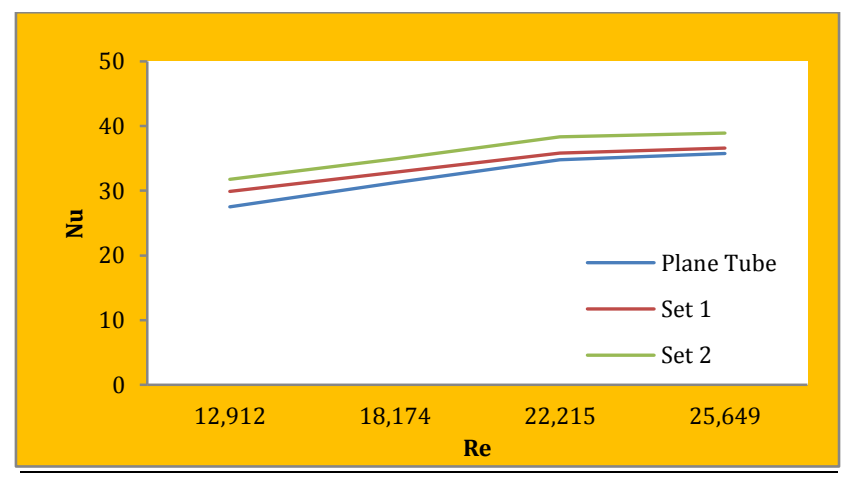

Fig.9 Reynolds Number verses Nusselt Number at 50W for different tubes

The above graph of heat input 50 Watt shows that grooved tubes shows increment in Nusselt number. Set1 tube shows $4.50 \%$ in comparison with plane tube and Set 2 tube shows $11.32 \%$ in comparison with plane tube.

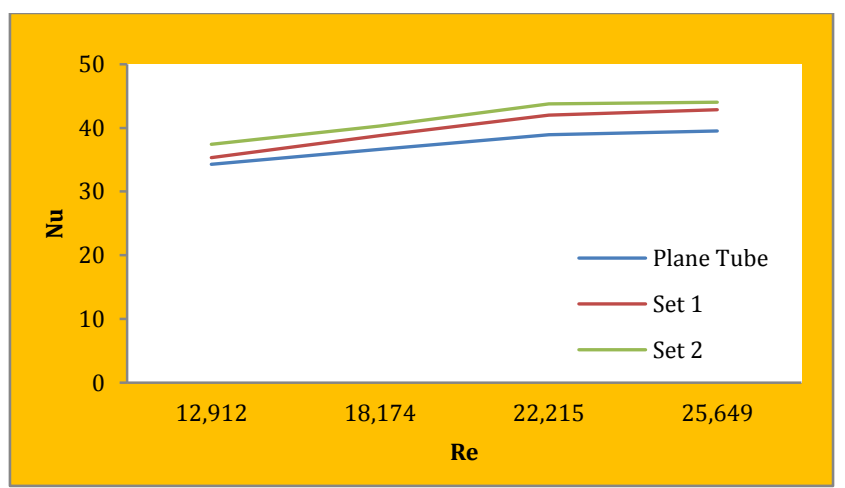

Fig.10 Reynolds Number verses Nusselt Number at 75W for different tubes 
The above graph of heat input 75 Watt shows that grooved tubes shows increment in Nusselt number. Set1 tube shows $6.47 \%$ in comparison with plane tube and Set 2 tube shows $10.83 \%$ in comparison with plane tube.

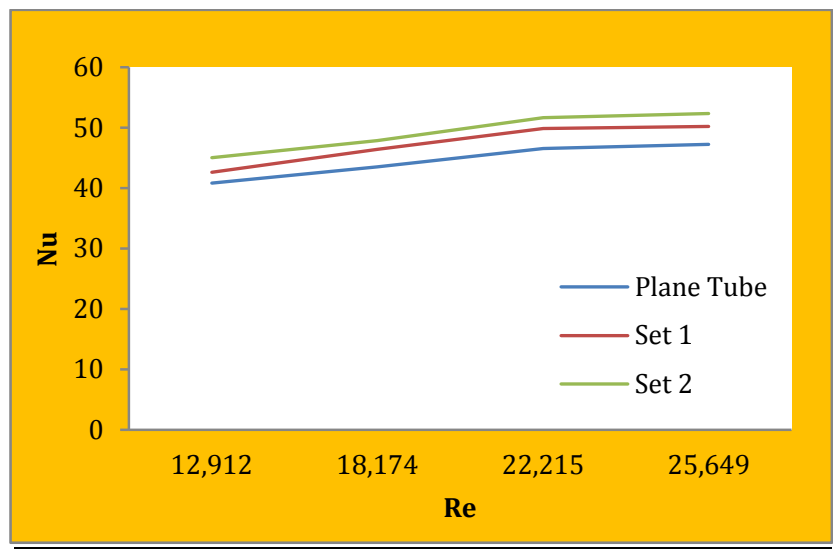

Fig.11 Reynolds Number verses Nusselt Number at 100W for different tubes

The above graph of heat input 100 Watt shows that grooved tubes shows increment in Nusselt number. Set 1 tube shows $6.13 \%$ in comparison with plane tube and Set2 tube shows $10.55 \%$ in comparison with plane tube.

\section{Conclusion}

In this study forced convection heat transfer characteristics from grooved tube has been investigated experimentally. The effect of variation in pitch of grooved has been investigated with variation in mass flow rate of air and heat input to grooved tube. The whole experimentation has been carried out under turbulent flow condition. This investigation was carried out to observe if the use of grooves on tube can enhance heat transfer characteristics for turbulent flow.

The following conclusions were drawn from this study.

- For 25W, 50W, $75 \mathrm{~W}$ and $100 \mathrm{~W}$, the enhancement in force convective heat transfer coefficient of set1 tube in compare with plane tube is observed as $6.89 \%, 4.48 \%, 6.49 \%$ and $6.13 \%$ respectively.
- $\quad$ For $25 \mathrm{~W}, 50 \mathrm{~W}, 75 \mathrm{~W}$ and $100 \mathrm{~W}$, the enhancement in convective heat transfer coefficient of set2 tube in compare with plane tube is observed as $13.56 \%$, $11.30 \%, 10.84 \%$ and $10.55 \%$ respectively.

- For 25W, 50W, 75W and 100W, the enhancement in Nusselt number of set1 tube in compare with plane tube is observed as 6.89\%, 4.50\%, 6.47\% and $6.13 \%$ respectively.

- For 25W, 50W, 75W and 100W, the enhancement in Nusselt number of set2 tube in compare with plane tube is observed as $13.54 \%, 11.52 \%, 10.83 \%$ and $10.55 \%$ respectively.

- Heat transfer enhancement under forced convection can be achieved by using grooved tubes. It is also observed that set 2 (20 pitch per feet) facilitates higher heat transfer augmentation when compared to the plane tube and set 1 (12 pitches per feet).

- Thus, the grooved on surface of the tube was found to enhance heat transfer over a plain tube surface for turbulent airflows.

\section{References}

KadirBilen , Murat Cetin , Hasan Gul , Tuba Balta, (2009), The Investigation of groove geometry effect for internally grooved tube, Applied Thermal Engineering 29, 753-76

Jacqueline Biancon Copetti, Mario Henrique Mecagnan, Daiana de Souza, Rejane De Cesaro Oliveski,(2004), Experiments with micro fin tube in single phase, International Journal of Refrigeration 27, 876-883.

Takahiro Adachi, Haruo Uehara, (2001), Correlation between heat transfer and pressure drop in channels with periodically grooved parts, International Journal of Heat and Mass Transfer 44, 4333-4343

M. Greiner, R. J. Faulker and R.A. Wirtz, (1997), Simulations of three-dimensional flow and Augmented Heat transfer in symmetrically grooved channel, Proceeding of Heat Transfer Division, Volume 3, 269-27

I. S. Park, D. H. Choi, (2001), Heat and Mass Transfer analysis for condensing film flow along a vertical grooved tube International Journal of Heat and Mass Transfer 44, 4277-4285. 